\title{
ECONOMIC EFFICIENCY OF SMALLHOLDER FARMERS IN WHEAT PRODUCTION: THE CASE OF ABUNA GINDEBERET DISTRICT, WESTERN ETHIOPIA
}

\author{
Milkessa ASFAW *1 (D), Endrias GETA ${ }^{2}$ (D), Fikadu MITIKU ${ }^{3}$ (iD)
}

\begin{abstract}
Address:
${ }^{1}$ Department of Agricultural Economics, Mizan Tepi University, College of Agriculture and Natural Resources, Mizan Teferi, Ethiopia

${ }^{2}$ South Agricultural Research Institute, Senior Researcher, Agricultural Economics Department

${ }^{3}$ Department of Agricultural Economics and Agribusiness Management, Jimma University, College of Agriculture and Veterinary Medicine, Jimma, Ethiopia

* Corresponding author: asfawso21@gmail.com
\end{abstract}

\begin{abstract}
Yield enhancement through increasing efficiency in cereal production in general and in wheat production in particular could be an important way towards achieving food security. This study was aimed at estimating the levels of technical, allocative and economic efficiencies of smallholder wheat producers; and to identify factors affecting efficiency of smallholder farmers in wheat production. A two stages sampling technique was used to select 152 sample farmers to collect primary data pertaining of 2016/17 production year. Both primary and secondary data sources were used for this study. Stochastic production frontier approach and two limit Tobit model was employed. The stochastic production frontier model indicated that input variables such as mineral fertilizers, land and seed were the significant inputs to increase the quantity of wheat output. The estimated mean values of technical, allocative and economic efficiency were 78, 80 and 63\% respectively, which indicate the presence of inefficiency in wheat production in the study area. A twolimit Tobit model result indicated that technical efficiency positively and significantly affected by sex of the household head, education, extension contact, off/non-farm activity and soil fertility but negatively affected by land fragmentation. Similarly, age, education, extension contacts and off/non-farm activity positively and significantly affected allocative efficiency. In addition, economic efficiency positively and significantly affected by sex, age, education, extension contact, off/non-farm activity and soil fertility. The policy measures derived from the results include: expansion of education, strengthening the existing extension services, establish and/or strengthening the existing off/non-farm activities and strengthening soil conservation practices in the study area.
\end{abstract}

Keywords: economic efficiency, Ethiopia, smallholder, stochastic frontier JEL: D24, D62

\section{INTRODUCTION}

Agriculture is a centre driver of Ethiopian economy. Economic growth of the country is highly linked to the success of the agricultural sector. It accounts for about $36.3 \%$ of the Gross Domestic Product, provides employment opportunities to more than $73 \%$ of total population that is directly or indirectly engaged in agriculture, generates about $70 \%$ of the foreign exchange earnings of the country and $70 \%$ raw materials for the industries in the country (UNDP, 2018). Even though it is contributing a lot to the Ethiopian economy, the agricultural sector is explained by low productivity, caused by a combination of natural calamities, demographic factors, socio-economic factors; lack of knowledge on the efficient utilization of available; and limited resources, poor and backward technologies and limited use of modern agricultural technologies (WFP, 2012). Moreover, the sector is dominated by smallholder farmers that are characterized by subsistence production with low input use and low productivity, and dependency on traditional farming and rainfall.

In sub-Saharan Africa, Ethiopia is the second largest producer of wheat, following South Africa. Wheat is one of the major staple and strategic food security crop in Ethiopia. It is the second most consumed cereal crop in Ethiopia next to maize. It is a staple food in the diets of several Ethiopian, providing about $15 \%$ of the caloric intake (FAO, 2015), placing it second after maize and slightly ahead of teff, sorghum, and enset, which contribute 10-12\% each (Minot et al., 2015).It has multipurpose uses in making human foods, such as bread, biscuits, cakes, sandwich, etc. Besides, wheat straw is commonly used as a roof thatching material and as a feed for animals (Mesfin, 2015).

In Oromia region, the total area covered by wheat was $898,455.57$ hectare produced by 2.21 million smallholders with the total production of 2.66 million tons; and average productivity was 2.96 ton/ha (CSA, 2017). In Abuna Gindeberet district, about 22,020 hectares of land was covered by cereal crops. Of these, 6,240 hectares of land was covered with wheat with total production of 174,721 
quintals. Despite its increase in area and production, its productivity is low (2.8ton/ha) which is below the average of productivity in the region (2.96ton/ha). There was also variation of productivity among wheat producers in the district due to difference in inputs application rates and management practices like timely sowing.

Production in efficient way is the basis for achieving overall food security and poverty reduction objectives particularly in major food crops producing potential areas of the country (Tolesa et al., 2014). However, farmers are discouraged to produce more because of inefficient agricultural production and efficiency differences among producers (Degefa et al., 2017). When there is inefficiency; attempts to commence new knowledge may not result in the expected impact since the existing knowledge is not efficiently utilized. The presence of inefficiency not only limits the gains from the existing resources, it also hinders the benefits that could arise from the use of improved inputs. Hence, improvement in the level of efficiency will increase productivity by enabling farmers to produce the maximum possible output from a given level of inputs with the existing level of technology (Geta et al., 2013; Yami et al., 2013; Sisay et al., 2015).

Many researchers, in different sectors, have done many efficiency estimation studies in Ethiopia. However, the majority of farm efficiency studies are limited to technical efficiency (Fekadu and Bezabih, 2008; Yami et al., 2013; Beshir, 2016; Kelemu and Negatu, 2016; Assefa, 2016; Tiruneh and Geta, 2016). But, focusing only on technical efficiency (TE) understates the benefits that could be derived by producers from improvements in overall performance. Unlike technical efficiency, studies conducted on economic efficiency (EE) of wheat are limited (Solomon, 2012; Awol, 2014). Moreover, there is no study done on economic efficiency of smallholder wheat producers in the study area. Therefore, the objectives of our study was to measure farm level technical, allocative and economic efficiencies of smallholder wheat producers and to identify factors that affect the level technical, allocative and economic efficiencies of smallholder wheat producers in Abuna Gindeberet District.

\section{DATA AND METHODS}

\section{Description of the Study Area}

The study was conducted in Abuna Gindeberet district in Ambo zone, Oromia National Regional State. The district is located at $184 \mathrm{~km}$ west of the capital city of the country, Finfinne. It is bordered by Meta Walkite district in East, Gindeberet district in West, Jeldu district in South and Amhara National Regional State in North. The total land area of the district is $138,483.25$ hectares which comprised 41 rural kebeles. Data collection for the study was carried out in three rural kebeles, viz., Jemmo feno, Gitire and Irjajo (Figure 1).

\section{Sampling Technique and Sample Size Determination}

Two stages random sampling procedures was employed to draw a representative sample. In the first stage, three kebeles out of the fifteen wheat producing kebeles in the district were randomly selected. In the second stage, 152 sample farmers were selected using simple random sampling technique based on probability proportional to the size of wheat producers in each of the three selected kebeles. To obtain a representative sample size, the study employed the sample size determination formula given by Yamane (1967) (Eq. 1).

$n=\frac{N}{1+N\left(e^{2}\right)}$

Where:

$n$ sample size; $N$ total number of wheat producing household heads in the district $(5,344) ; e$ margin error $(8 \%)$

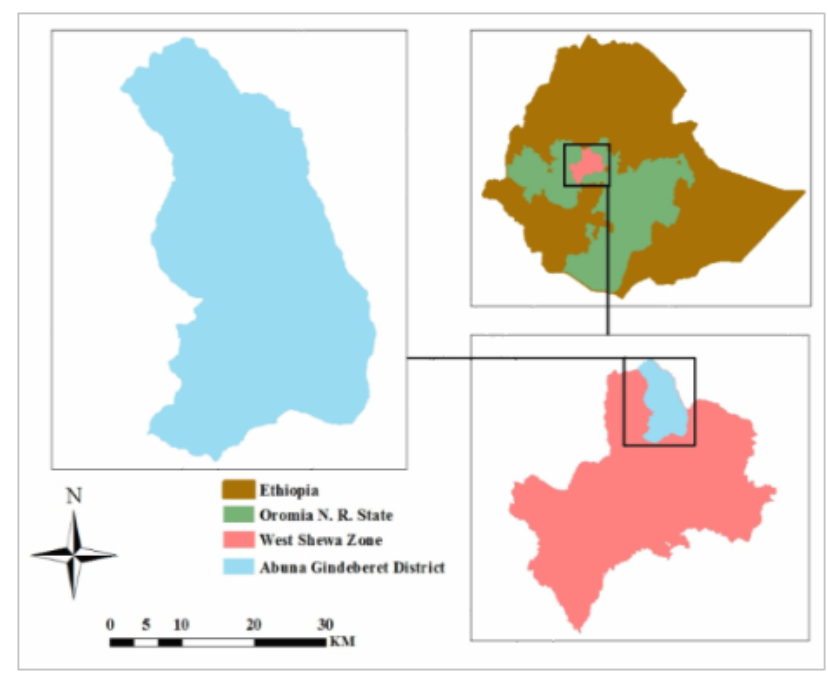

Figure 1. Map of the study area

\section{Data Collection}

Both qualitative and quantitative data were used. Data was obtained from both primary and secondary data sources. The primary data were collected using structured questionnaire that was administered by the trained enumerators. The questionnaire was pre-tested and necessary corrections were made before actual use. Secondary data were also collected from bureau of agriculture of the district and other relevant sources.

\section{Methods of Data Analysis}

Both descriptive and econometric methods were used to analyse the data. Descriptive statistics, mean, minimum, maximum and standard deviations were used.

Most empirical studies on efficiency in Ethiopia were analysed using stochastic production frontier methodology (Solomon, 2014; Ahmed et al, 2015; Sisay et al., 2015).This study also employed stochastic frontier approach to estimate the level of technical, allocative and economic efficiencies. The main reason is that stochastic approach allows for statistical noise such as measurement error and climate change which are beyond the control of the decision making unit.

Following Aigner et al. (1977) the model is specified by Eq. 2.

$\ln \left(Y_{i}\right)=F\left(X_{i}, \beta_{i}\right)+v_{i}-\mu_{i} \quad i=1,2,3 \ldots N$ 
Where:

$i$ denotes the number of sample households;

$\ln (Y i)$ denotes the natural $\log$ of (scalar) output of the $\mathrm{i}^{\text {th }}$ households;

$X_{i}$ represent a vector of input quantities used by the $\mathrm{i}^{\text {th }}$ households;

$\beta_{i}$ denotes a vector of unknown parameters to be estimated;

$v_{i}$ is a symmetric component and permits a random variation in output due to factors beyond the control of farmers. It is assumed to be independently and identically distributed $N \sim\left(0, \sigma_{v}^{2}\right)$ and

$u_{i}$ intended to capture inefficiency effects in the production of wheat measured as the ratio of observed output to maximum feasible output of the $\mathrm{i}^{\text {th }}$ farm. It is assumed to be independently and identically distributed as half-normal, $u \sim N\left(u, \sigma^{2}{ }_{u}\right)$. The study computes TE for the $\mathrm{i}^{\text {th }}$ firms as Eq. 3 .

$\mathrm{TE}=\frac{\ln Y_{i}=\beta_{o}+\sum_{j=1}^{5} \beta_{j} \ln X_{j i}+v_{i}-u_{i}}{\ln Y_{i}=\beta_{o}+\sum_{j=1}^{5} \beta_{j} \ln X_{j i}+v_{i}}=\frac{Y_{i}}{Y_{i}{ }^{*}}$

The value of TE lies between zero and one implying fully technically inefficient and fully technically efficient respectively. Following Battese and Coelli (1995) the stochastic cost frontier function was specified which forms the basis of computing $\mathrm{AE}$ and $\mathrm{EE}$ of wheat production. The dual cost frontier is specified as in Eq. 4.

$\ln \llbracket\left(C \rrbracket_{i}\right)=\beta_{o}+\sum_{j=1}^{5} \beta_{j} \ln P_{j i}+v_{i}+u_{i}$

Where:

$\ln C_{\mathrm{i}}$ denotes the logarithm of the cost of production of the $\mathrm{i}^{\text {th }}$ firm;

$P_{j i}$ denotes a vector of inputs price and output of $\mathrm{i}^{\text {th }}$ firm; $\beta_{o}, \beta_{j}$ denotes a vector of unknown parameter to be estimated;

$v_{i}$ denotes random variables assumed to be independent and identically distributed random errors with zero mean and variance $\left(\sigma v^{2}\right)$ and

$u_{i}$ denotes non-negative random variables which are assumed to account for cost inefficiency.

After we estimate cost efficiency, allocative efficiency is computed as the inverse of cost efficiency. Economic efficiency was computed by the product of technical and allocative efficiencies.

\section{Determinants of efficiency}

In this study, to identify the effect of independent variables on level of efficiencies, two-limit Tobit model was employed. Because of the character of the dependent variable which is efficiency score that takes values between 0 and 1 the model is appropriate (Maddala, 1999).

Following Maddala (1999) the model can be specified as in Eq. 5.

$y_{i T E, A E, E E}^{*}=\delta_{0}+\sum_{n=1}^{12} \delta_{n} Z_{i n}+\mu_{i}$

Where: $\mathrm{i}$ refers to the $\mathrm{i}^{\text {th }}$ farm in the sample households; $\mathrm{n}$ is the number of factors affecting efficiencies scores; $y_{i}$ is efficiency scores of the $\mathrm{i}^{\text {th }}$ farm. $y_{i}^{*}$ is the latent variable, $\delta_{n}$ are unknown parameters to be estimated and $\mu_{i}$ is a random error term that is independently and normally distributed with mean zero and common variance of $\sigma^{2}\left(\mu_{\mathrm{i}} \sim \mathrm{IN}\left(0, \sigma^{2}\right)\right) . Z_{\text {in }}$ are demographic, institutional, soci-economic and farm-related variables which are expected to affect the dependent variable (level of efficiencies in this study).

Denoting $y i$ as the observed variables (Eq. 6),

$y_{i}=\left|\begin{array}{cc}1 & \text { if } y_{i}^{*} \geq 1 \\ y_{i}^{*} \quad \text { if } 0<y_{i}^{*}<1 \\ 0 \quad \text { if } y_{i}^{*} \leq 0\end{array}\right|$

Since the distribution of the explained variable in equation (5) is not normal the ordinary least square (OLS) estimation will give biased estimates (Maddala, 1999). To avoid the biased estimates arrives from OLS, the maximum likelihood estimation can give up the reliable estimates for unknown parameters. Following Maddala (1999), the likelihood function of this model is given by Eq. 7.

$$
\begin{aligned}
& L\left(\beta, \delta \mid y_{j}, X_{j} L_{1 j}, L_{2 j}\right)=\prod_{y_{j}=L_{1 j}} \varphi\left(\frac{L_{1 j}-\beta^{\prime} X_{j}}{\delta}\right) \prod_{y_{j}=y_{j}^{*} \frac{1}{\delta}} \phi \\
& \left(\frac{y_{j}-\beta^{\prime} X_{j}}{\delta}\right) \prod_{y_{j}=L_{2 j}} 1-\varphi\left(\frac{L_{2 j}-\beta^{\prime} X_{j}}{\delta}\right)
\end{aligned}
$$

Where: $L_{1 j}=0$ (lower limit) and $L_{2 j}=1$ (upper limit) where $\varphi($.$) and \phi($.$) are normal and standard density$ functions. It is better to work with log of likelihood function rather than likelihood since the $\log$ function is monotonically increasing function (Greene, 2003).

Like traditional regression coefficients, the regression coefficients of the two-limit Tobit regression model cannot be interpreted, that give the extent of the marginal effects of change in the predictor variables on the likely value of the response variable. In a Tobit model, each marginal effect includes both the influence of explanatory variables on the probability of explained variable to fall in the uncensored part of the distribution and on the expected value of the dependent variable conditional on it being larger than the lower bound. Thus, the total marginal effect takes into account that a change in independent variable will have a simultaneous effect on probability of being technically, allocatively and economically efficient and value of technical, allocative and economic efficiency scores. A useful breakdown of marginal effects was extended by Gould et al. (1989). From the likelihood function of the model stated in equation (7), Gould $\boldsymbol{e t}$ al. (1989) proved the equations of three marginal effects as follows:

a. The unconditional expected value of the dependent variable (Eq. 8).

$$
\begin{aligned}
& \frac{\partial \mathrm{E}(\mathrm{y})}{\partial \mathrm{x}_{\mathrm{j}}}=\left[\varphi\left(\mathrm{Z}_{\mathrm{U}}\right)-\varphi\left(\mathrm{Z}_{\mathrm{L}}\right)\right] \cdot \frac{\partial \mathrm{E}\left(\mathrm{y}^{*}\right)}{\partial \mathrm{x}_{\mathrm{j}}}+\frac{\partial\left[\varphi\left(\mathrm{Z}_{\mathrm{U}}-\varphi\left(\mathrm{Z}_{\mathrm{L}}\right)\right]\right.}{\partial \mathrm{x}_{\mathrm{j}}}+ \\
& \frac{\partial\left(1-\varphi\left(\mathrm{Z}_{\mathrm{U}}\right)\right.}{\partial \mathrm{x}_{\mathrm{j}}}
\end{aligned}
$$


b. The expected value of the dependent variable conditional upon being between the limits (Eq. 9).

$$
\begin{aligned}
& \frac{\partial \mathrm{E}\left(\mathrm{y}^{*}\right)}{\partial \mathrm{x}_{\mathrm{j}}}=\beta_{\mathrm{n}} \cdot\left[1+\frac{\left\{\mathrm{z}_{\mathrm{L}} \phi_{\left(\mathrm{Z}_{\mathrm{L}}\right)-\mathrm{Z}_{\mathrm{U}}} \phi_{\left.\left(\mathrm{Z}_{\mathrm{U}}\right)\right\}}\right)}{\left\{\left(\varphi\left(\mathrm{Z}_{\mathrm{U}}\right)-\varphi\left(\mathrm{Z}_{\mathrm{L}}\right)\right\}\right\}}\right]- \\
& {\left[\frac{\left\{\phi_{\left(\mathrm{Z}_{\mathrm{L}}\right)-} \phi_{\left.\left(\mathrm{Z}_{\mathrm{U}}\right)\right\}^{2}}\right.}{\left\{\varphi\left(\mathrm{Z}_{\mathrm{U}}\right)-\varphi\left(\mathrm{Z}_{\mathrm{L}}\right)\right\}^{2}}\right]}
\end{aligned}
$$

c. The probability of being between the limits (Eq. $10)$.

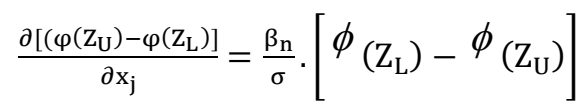

Where: $\varphi($.$) the cumulative normal distribution, \phi($.$) the$ normal density function, $\mathrm{Z}_{\mathrm{L}}=-\beta^{\prime} \mathrm{X} / \sigma$ and $\mathrm{Z}_{\mathrm{U}}=(1-$ $(\beta \mathrm{X})) / \sigma$ are standardized variables that came from the likelihood function given the limits of $\mathrm{y}^{*}$, and $\sigma$ standard deviation of the model. The marginal effects represented by the equations above were calculated by the STATA command.

Hypothesis tests that cannot be applied in nonparametric models, are possible in stochastic production frontier model. Different hypothesis tests were made for this study by using the likelihood ratio (LR) test given by Equation (11) following Greene (2003).
$L R(\lambda)=-2 \ln \left[L\left(H_{o}\right)\right]-\ln \left[L\left(H_{1}\right)\right]$

Where:

$\mathrm{L}\left(\mathrm{H}_{0}\right)$ likelihood function value under $\left(\mathrm{H}_{0}\right)$;

$\mathrm{L}\left(\mathrm{H}_{1}\right)$ likelihood function value under $\left(\mathrm{H}_{1}\right)$.

In most cases, this function has an asymptotic chisquare distribution. Thus, if the value of LR $(\lambda)$ exceeds the critical/tabulated $\chi^{2}$ statistic, then the null hypothesis would be rejected in favour of the alternative and vice versa. All the parameters of production frontier, dual cost frontier and two limit Tobit model were estimated using STATA.

\section{RESULTS AND DISCUSSION}

On average, the sampled households produced 15.08 qt of wheat, which is the regressand variable in the production function. The land allocated for wheat production, by sampled households during the survey period was ranged from 0.125 to 2.5 ha with an average of 0.712 ha. Similarly, on average the sampled farmers incurred 13,607.46 birr to produce 15.08 quintal of wheat. Among the five factors of production, the cost of land and labour accounted the highest share 30.79 and $27.79 \%$, respectively (Table 1 ).

The review statistics of demographic, socioeconomic, farm and institutional variables which were expected to affect technical, allocative and economic efficiency levels of smallholder farmers in the study area are presented in Table 2 and 3 .

Table 1.Summary statistics of variables used to estimate the production and cost function

\begin{tabular}{llllll}
\hline Variables & Unit & Mean & Std.Dev. & Min & Max \\
\hline Output & Quintal & 15.08 & 10.8 & 2 & 57 \\
Seed & Kilogram & 122.75 & 85.57 & 20.00 & 445 \\
Land & Hectare & 0.712 & 0.45 & 0.125 & 2.5 \\
Labour & Man-days & 62.21 & 37.4 & 10.00 & 215.6 \\
Mineral fertilizers & Kilogram & 118.09 & 82.9 & 20.00 & 525 \\
Oxen & Oxen-days & 29.43 & 15.62 & 5.00 & 81 \\
Total cost of production & Birr & $13,607.46$ & $10,274.58$ & 1,700 & 59,850 \\
Cost of seed & Birr & $9,73.48$ & 900.65 & 131.25 & 6500 \\
Cost of land & Birr & $4,037.45$ & $2,492.11$ & 678.12 & 12000 \\
Cost of labour & Birr & $3,644.37$ & $2,199.40$ & 650 & 11858 \\
Cost of mineral fertilizers & Birr & $1,240.15$ & 888.17 & 202.8 & 6037.5 \\
Cost of oxen & Birr & $3,217.05$ & $1,767.18$ & 475 & 11400 \\
\hline
\end{tabular}

Source: own computation (2018)

Table 2.Summary of continuous variables used in efficiency model

\begin{tabular}{lllll}
\hline Variables & Sample mean & Std. deviation & Min. & Max. \\
\hline Age of the household head (years) & 47.89 & 10.05 & 24 & 75 \\
Family size (ME) & 6.12 & 1.80 & 2 & 11.4 \\
Educational level (years) & 5.82 & 3.04 & 0 & 12 \\
Frequency of extension contact & 5.69 & 2.69 & 0 & 12 \\
Cultivated land (ha) & 0.84 & 0.70 & 0.25 & 3.5 \\
Livestock (TLU) & 6.95 & 3.17 & 1.68 & 15.15 \\
Distance to the nearest market (min) & 32.97 & 13.32 & 3 & 55 \\
Land fragmentation & 2.08 & 0.85 & 1 & 4 \\
\hline
\end{tabular}

Source: own computation (2018) 
Table 3. Summary of dummy variables used in efficiency model

\begin{tabular}{llll}
\hline Variables & Description & Frequency & Percentage \\
\hline Sex of the household head & Male (1) & 118 & 77.63 \\
& Female & 34 & 22.37 \\
Fertility status of the soil & Yes (Fertile) (1) & 112 & 73.68 \\
& No (Infertile) & 40 & 26.32 \\
Credit utilization & Used (1) & 89 & 58.55 \\
& Not used & 63 & 41.45 \\
Participation in off/non-farm activities & Yes (1) & 103 & 67.76 \\
& No & 49 & 32.24 \\
\hline
\end{tabular}

Source: own computation (2018)

\section{Hypotheses test}

In this study, three hypotheses were tested. Accordingly, the functional form that can best fit to the data at hand was selected by testing the null hypothesis which states that the coefficients of all interaction terms and square specifications in the translog functional forms are equal to zero $\left(\mathrm{H}_{0}: \beta_{\mathrm{ij}}=0\right)$ against alternative hypothesis $\left(\mathrm{H}_{1}: \beta_{\mathrm{ij}} \neq 0\right)$. This test was made based on the value of likelihood ratio (LR) statistics which could be computed from the log likelihood values of both the Cobb-Douglas and Translog functional forms using Equation 12.

$\lambda=-2\left[\log L\left(H_{0}\right)-\log L\left(H_{1}\right)\right]$

The $\lambda$ value computed by the above formula was compared with the upper $5 \%$ critical value of the $\chi^{2}$ at the degree of freedom equals to the difference between the number of independent variables used in both functional forms (in this case degree of freedom $=15$ ). Accordingly, the $\log$ likelihood functional values of both Cobb-Douglas and Translog production functions were -34.84 and -26.32 respectively. Therefore, the $\lambda$ value computed was 17.04 and this value is lower than the upper $5 \%$ critical value of $\chi^{2}$ at 15 degrees of freedom (24.9) (Table 4). As a result, the null hypothesis was accepted and the Cobb-Douglas functional form best fits the data.

The second test is to test the null hypothesis that the inefficiency component of the total error term is equal to zero $(\gamma=0)$ and alternative hypothesis that inefficiency component different from zero. Thus, the likelihood ratio is calculated and compared with the $\chi^{2}$ value at a degree of freedom equal to the number of restrictions (the inefficiency component) estimated by the full frontier, which is 1 in this case for all models.

As explained in Table 4, one-sided generalized $\lambda$ test of $\gamma=0$ provide a statistics of 12.2 for wheat production; which is significantly higher than the critical value of $\chi^{2}$ for the upper 5\% at one degree of freedom (3.84). As a result, the null hypothesis that states wheat producers in the study area are fully efficient is rejected.

The third hypothesis tested was that all coefficients of the inefficiency effect model are simultaneously equal to zero (i.e. $\mathrm{H}_{0}: \delta_{0}=\delta_{1}=\delta_{2}=\cdots \delta_{12}=0$ ) against the alternative hypothesis, which states that all parameter coefficients of the inefficiency effect model are not simultaneously equal to zero. It was also tested in the same way by calculating the $\lambda$ value using the value of the $\log$ likelihood function under the stochastic frontier model (without explanatory variables of inefficiency effects, $\mathrm{H}_{0}$ ) and the full frontier model (with variables that are supposed to determine efficiency level of each farmer, $\mathrm{H}_{1}$ ). Using the formula in Equation (12), the value $\lambda$ obtained was 77.56 , which is higher than the critical $\chi^{2}$ value $(21.03)$ at the degree of freedom equal to the number of restrictions to be zero (in this case the number of coefficients of the inefficiency effect model was 12). As a result, the null hypothesis is rejected in favour of the alternative hypothesis that explanatory variables associated with inefficiency effect model are simultaneously not equal to zero.

\section{The MLE of the parametric stochastic production frontier}

Given the specification of Translog, the Cobb-Douglas stochastic production was tested and found to best fit to the data and was used to estimate efficiency of farmers. The dependent variable of the estimated production function was wheat output $(\mathrm{Qt})$ and the input variables used in the analysis were area under wheat (ha), oxen (pair of oxen-days), labour (man-days in man-equivalent), quantity of seed $(\mathrm{kg})$ and quantity of fertilizer $(\mathrm{Kg})$.

Land allotted for wheat production and mineral fertilizers are found to be statistically significant at $1 \%$ significance level implying that increasing the level of these inputs would increase wheat yield in the study area. Mineral fertilizers also appeared to be an important factor, with coefficient of 0.353 . This implies that a $1 \%$ increase in mineral fertilizers enhance wheat output by about $0.35 \%$ at ceterius paribus. This result is in line with the empirical results of Fekadu and Bezabih (2008), Tolesa et al.(2014), Sisay et al.(2015), Ahmed et al. (2015), Mekonnen et al. (2015), Tiruneh and Geta (2016), Beshir (2016), Mustefa et al. (2017) and Nigusu (2018).

The coefficients related with the inputs measure the elasticity of output with respect to inputs. The results showed that the input variables specified in the model had elastic effect on the output of wheat production. The scale coefficient calculated was 1.214 , indicating increasing returns to scale. This implies that there is potential for wheat producers to expand their production because they are in the stage I production area. This implies that, a $1 \%$ increase in all inputs proportionally would increase the total production of wheat by $1.214 \%$. Therefore, an increase in all inputs by $1 \%$ would increase wheat output by more than $1 \%$. 
Table 4. Generalized Likelihood Ratio test of hypotheses for parameters of SPF

\begin{tabular}{lllll}
\hline Null hypothesis & Df & $\lambda$ & Critical value & Decision \\
\hline $\mathrm{H}_{\mathrm{o}}: \beta_{\mathrm{ij}}=0$ & 15 & 17.04 & 24.9 & Accept $\mathrm{H}_{0}$ \\
$\mathrm{H}_{\mathrm{o}}: \gamma=0$ & 1 & 12.2 & 3.84 & Reject $\mathrm{H}_{0}$ \\
$\mathrm{H}_{\mathrm{o}}: \delta_{0}=\delta_{1}=\delta_{2}=\cdots \delta_{12}=0$ & 12 & 77.56 & 21.03 & Reject $\mathrm{H}_{0}$ \\
\hline
\end{tabular}

Table 5. Estimates of the Cobb Douglas frontier production function

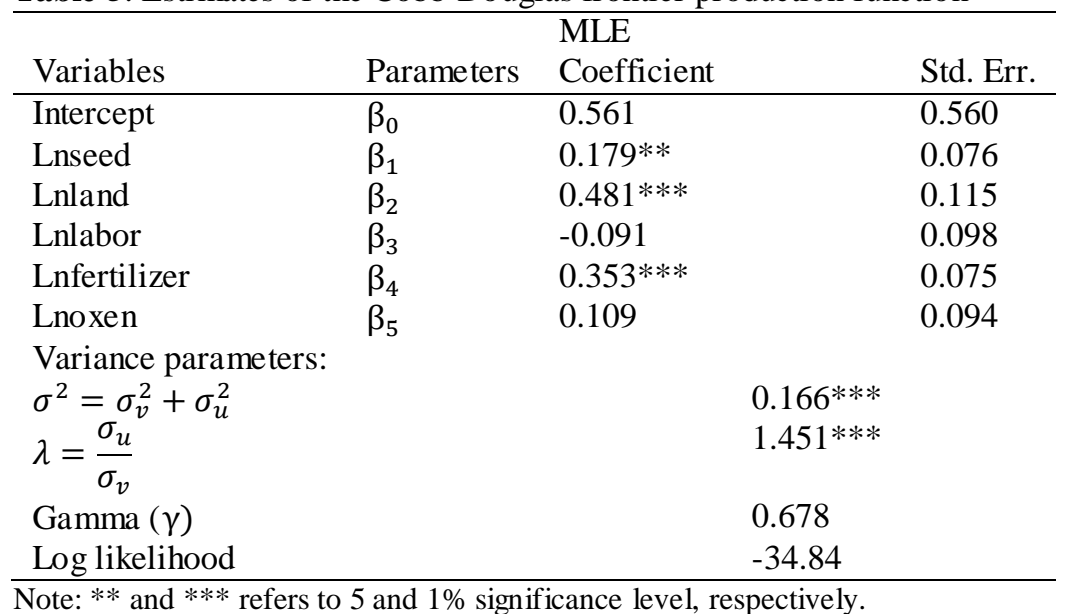

Note: $* *$ and $* * *$ refers to 5 and $1 \%$ significance level, respectively.

Source: Model output (2018)

This result is consistent with the empirical results of Beshir (2016) and Assefa (2016) who estimated the returns to scale of 1.33 and $1.38 \%$ in the study of technical efficiency of wheat production in South Wollo and Hadiya zone, Ethiopia respectively.

The diagnostic statistics of inefficiency component reveals that sigma squared $\left(\sigma^{2}\right)$ was statistically significant which indicates goodness of fit, and the correctness of the distributional form assumed for the composite error term. The estimated value of Gamma $\gamma$ is 0.6778 which indicates that $67.78 \%$ of total variation in farm output from the frontier is due to technical inefficiency and the remaining $32.22 \%$ was due to factors beyond the control of farmers. The dual frontier cost function derived analytically from the stochastic production frontier shown in Table 5 is given by Eq. 13 .

$$
\begin{aligned}
& \ln C i=3.47+0.07 \ln w_{1 i}+0.26 \ln w_{2 i}+0.02 \ln w_{3 i}+ \\
& 0.23 \ln w_{4 i}+0.02 \ln w_{5 i}+0.48 \ln Y_{i}^{*}(13)
\end{aligned}
$$

Where: $C_{i}$ is the minimum cost of production of the $\mathrm{i}^{\text {th }}$ farmer, $\mathrm{Y}^{*}$ refers to the index of output adjusted for any statistical noise and scale effects and wstands for input costs.

\section{Efficiency scores and their distribution}

The mean TE of sample farmers was about 0.78. This means that if the average farmer in the sample was to achieve the technical efficient level of its most efficient counterpart, then the average farmer could realize $17.12 \%$ derived from (1-0.784/0.946)*100 increase in output by improving technical efficiency with existing inputs and technology. The average AE of the sample farmers was about 0.80 . This shows that farmers are not allocatively efficient in producing wheat and hence, a producer with the mean score of allocative efficiency should have outlay saving of about17.19\% .Similarly, the mean EE of the sample farmers was 0.63 implying there is low level of economic efficiency in wheat production in the study area. The estimated average efficiency levels of smallholder wheat producers in the study area (Table 6) can be compared to other efficiency studies made in different parts of our country. Consequently, Nigusu (2018) found mean TE, AE and EE of $0.79,0.83$ and 0.66 respectively for teff producers in Northern Shewa, Ethiopia. In addition, Solomon (2012) found mean TE, AE and EE of $0.79,0.47$ and 0.37 respectively for wheat seed producer farmers in West Gojjam, Ethiopia.

Table 6: Estimated technical, allocative and economic efficiency scores

\begin{tabular}{lllll}
\hline $\begin{array}{l}\text { Types of } \\
\text { efficiency }\end{array}$ & Mean & Std.Dev. & Min & Max. \\
\hline TE & 0.784 & 0.090 & 0.289 & 0.946 \\
AE & 0.809 & 0.114 & 0.343 & 0.977 \\
EE & 0.635 & 0.109 & 0.099 & 0.911 \\
\hline
\end{tabular}

Source: Model output (2018)

The distribution of the technical efficiency scores showed that about $47.36 \%$ of the sample households had technical efficiency score of between 80 to $90 \%$. The allocative efficiency distribution scores indicated that about $27.63 \%$ of wheat producers operated above $90 \%$ efficiency level. The distribution of economic efficiency scores implies that $36.18 \%$ of the household heads have an economic efficiency score of 50-60\%. This indicates the existence of low economic efficiency than technical and allocative efficiencies in the production of wheat during the study period in the study area (Figure 2). 


\section{Determinants of efficiency}

A two limit Tobit model was used to identify factors that affect efficiency levels among the sampled farmers. In this study, the dependent variable is efficiency scores not inefficiency. Thus, the marginal effect should be interpreted as their effect on efficiency and not inefficiency and if one wants to use inefficiency, the sign of the marginal effect, has to be changed.

The finding of the study shows that age affected allocative and economic efficiency of the smallholder farmers in wheat production positively and significantly at 10 and $1 \%$ significance level, respectively. This implies that older farmers were more efficient than younger ones. This was probably because older farmers may have better experience in farming. Moreover, farmers at older age may accumulate good control of resources like oxen, farm tools and labour that could boost their efficiency, since in crop production, better availability of farm resources enhances timely application of inputs that increase efficiency of the farmer (Kitila and Alemu, 2014).Furthermore, the computed marginal effect of age of the household head showed that, a one year increase in the age of the household head would increase the probability of the farmer being allocative efficient by about $0.13 \%$ and the mean value of allocative and economic efficiency by 0.12 and $0.14 \%$ with an overall increase in the probability and the level of allocative and economic efficiencies by 0.14 and $0.14 \%$, respectively (Table 8). This result is in line with the findings of Ali $\boldsymbol{e t}$ al. (2012), Kitila and Alemu (2014) and Alemu and Haji (2016).

The coefficient for sex of the household head was significant and positively affected technical and economic efficiencies of farmers at $1 \%$ significance level, as it was expected (Table 7). It indicated male headed households operating more efficiently than their female counterparts. This result is in line with the findings of Tiruneh and Geta (2016) and Meftu (2016). As expected, educational level of the household head had a positive and significant effect on TE, and $\mathrm{AE}$ at $5 \%$ and $\mathrm{EE}$ of wheat production at $1 \%$ level of significance. This is because education can increase their information gaining and adjustment abilities, thereby- increasing their decision making capacity. In line with this study, research done by Solomon (2012), Ahmed et al. ( 2013), Sisay et al. (2015) and Ahmed et al. (2015)explains that the more educated the farmer, the more technically, allocative and economically efficient $\mathrm{s} /$ he becomes.

Soil fertility was positively and significantly affected technical and economic efficiencies at 1 and 5\% level of significance, respectively (Table 7). This implies that farmers who have allocated fertile land for wheat production were more technically and economically efficient than their counterparts. This result is consistent with the empirical findings of (Fekadu and Bezabih, 2008; Awol, 2014; Mekonnen et al., 2015; Assefa, 2016). Frequency of extension contact had significant and positive effect on technical efficiency at $5 \%$, allocative and economic efficiencies at $1 \%$ significance level, respectively. This indicates households who receive more extension contacts by extension workers appear to be more efficient than their counterparts. This result is similar with the findings of Ahmed et al. (2013), Kitila and Alemu (2014), Sisay et al. (2015) and Nigusu (2018).

The coefficient of participation in off/non-farm activity was positive and significant for technical and economic efficiency at $1 \%$ whereas allocative efficiency at $5 \%$ significance level (Table 7). This effect is may be due to the income obtained from such activities could be used for the purchase of agricultural inputs, and it shifts the cash constraint outwards and enables farmers to make timely purchase of those inputs which they cannot provide from on farm income. This result is in line with the empirical findings of Haji (2008), Solomon (2012) and Kitila and Alemu (2014). The coefficient of land fragmentation for technical efficiency is negative and statistically significant at $10 \%$ significance level as it was expected. The result confirms the expectation, because fragmented land leads to reduce efficiency by creating lack of family labour, wastage of time and other resources that would have been available at the same time. This result is in line with the empirical results of Assefa (2016) and Mustefa et al. (2017).

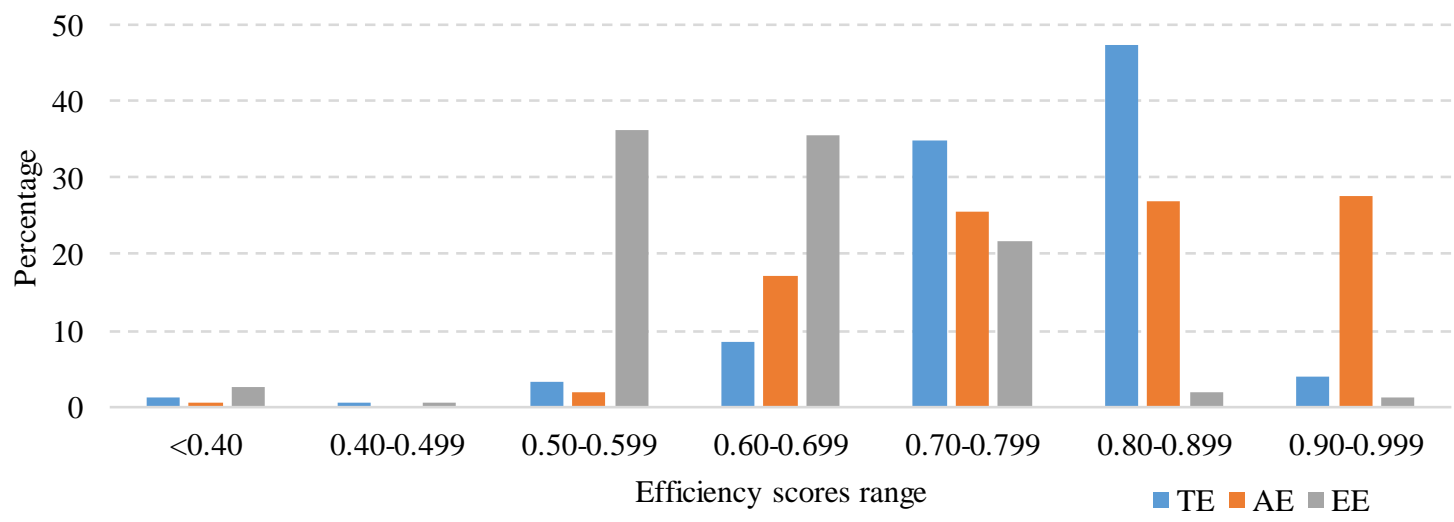

Figure2. Frequency distribution of technical, allocative and economic efficiencies scores Source: Computed based on model results 
Table 7: Tobit regression results of determinants of technical, allocative and economic efficiency

\begin{tabular}{lllllll}
\hline Variable & TE & \multicolumn{3}{c}{ AE } & EE & \\
& Coefficient & Std.Err & Coefficient & Std.Err & Coefficient & Std.Err \\
\hline Constant & $0.6402 * * *$ & 0.0461 & $0.5994 * * *$ & 0.0611 & $0.3656^{* * *}$ & 0.0423 \\
AGEHH & 0.0007 & 0.0006 & $0.0015 *$ & 0.0008 & $0.0014 * * *$ & 0.0005 \\
SEXHH & $0.0821 * * *$ & 0.0148 & -0.0127 & 0.0196 & $0.0516 * * *$ & 0.0136 \\
EDUCLHH & $0.0048^{* *}$ & 0.0022 & $0.0068 * *$ & 0.0029 & $0.0088^{* * *}$ & 0.0020 \\
FOEC & $0.0053 * *$ & 0.0027 & $0.0166^{* * *}$ & 0.0035 & $0.0171 * * *$ & 0.0024 \\
PONFAC & $0.0472 * * *$ & 0.0136 & $0.0375 * *$ & 0.0181 & $0.0648 * * *$ & 0.0125 \\
SOILFERT & $0.0375^{* * *}$ & 0.0137 & 0.0028 & 0.0182 & $0.0252 * *$ & 0.0126 \\
LANDFR & $-0.0135^{*}$ & 0.0070 & -0.0008 & 0.0093 & -0.0082 & 0.0064 \\
\hline NOte:
\end{tabular}

Note: $* * *$ and $* * *$ refers to level of significance at 10,5 and $1 \%$ respectively.

Source: Model output (2018)

\section{CONCLUSION AND RECOMMENDATIONS}

Result of the production function indicated that seed, land and mineral fertilizers were the significant inputs, with positive sign as expected. Among the three significant inputs, mineral fertilizers and land under wheat production had significant and positive influence on wheat production at less than $1 \%$ level of significance. This depicts that farmers who allocated more land for wheat production and those who applies more amount of mineral fertilizers receive higher wheat yields. The coefficients related with the inputs measure the elasticity of output with respect to inputs. The results showed that the input variables specified in the model had elastic effect on the output of wheat production. The coefficient calculated was 1.214, indicating increasing returns to scale. This implies that, an increase in all inputs by $1 \%$ would increase wheat output by more than $1 \%$ in the study area.

The estimated mean values of technical, allocative and economic efficiency levels were 78, 80 and 63\%, respectively. This implied that there is an opportunity for wheat producers to increase wheat output at existing levels of inputs and minimize cost without compromising yield with present technologies available in the hands of producers.

Education, extension and participation in off/nonfarm activity had positive and significant effect on technical, allocative and economic efficiencies. This shows that more educated farmers, the more farmers have contact with extension agent and farmers participating in off/non-farm activities were more technically, allocatively and economically efficient than their counterparts respectively. In addition, as it was expected sex and soil fertility had positive and significant effect on technical and economic efficiencies, implying that male headed households, household heads who allocate fertile land for wheat production were more technically and economically efficient than their counterparts, respectively. Similarly, age had a positive and significant effect on allocative and economic efficiencies, which implies that older household heads were more efficient than their counterparts. Moreover, land fragmentation had negative and significant impact on technical efficiency.

Based on the results of the study, the following policy recommendations have been drawn. First, using best practices of the efficient farmers as a point of reference would help setting targets in improving efficiency levels and finding the weakness of the present farm practices. The relatively efficient farms can also improve their efficiency more through learning the best resource allocation decision from others. This can be achieved by arranging field days, cross-visits, creating forum for experience sharing with elder households and on job trainings.

Age showed a positive and significant effect on efficiency. Therefore different mechanisms should be devised to encourage farmers with little experience to work with the experienced ones or train them. The results of the study also shows, as female household heads were less efficient than male household heads. Thus, provision of improved technologies that can help female farmers in decreasing their home burden and this would in turn help them to improve their efficiency level in wheat production have to be practiced in the study area.

In the study area, education of household heads had positive and significant effect on technical, allocative and economic efficiencies. Hence, the key policy implication is that appropriate policy should be designed to provide adequate and effective basic educational opportunities for farmers in the study area. Extension contact has positive and significant effect on technical, allocative and economic efficiencies in the study area. Therefore, suitable and sufficient extension services should be provided for wheat producers. The study also found that, participation in off/non-farm activity had a positive and significant effect on technical, allocative and economic efficiencies. Therefore, strategies that enhance the ease use of off/non-farm employment opportunities would help to increase the timely and appropriate use of inputs for better efficiency in wheat production in the study area. Moreover, technical and economic efficiency were positively and significantly affected by soil fertility. Therefore, improvement of the soil status by applying organic manures and practicing different soil conservation techniques should have to done by farmers.

\section{Acknowledgements}

Special gratitude goes to farmers who participated in this study and development agents of Abuna Gindeberet District for their cooperation during data collection. 
Table 8. The marginal effects of change in explanatory variables

\begin{tabular}{|c|c|c|c|c|c|c|c|c|c|}
\hline \multirow[t]{3}{*}{ Variables } & \multicolumn{2}{|c|}{ Marginal effects (TE) } & & \multicolumn{2}{|c|}{ Marginal effects (AE) } & \multicolumn{3}{|c|}{ Marginal effects (EE) } & \multirow{3}{*}{$\frac{\partial\left[\left(\varphi\left(\mathrm{Z}_{\mathrm{U}}\right)-\varphi\left(\mathrm{Z}_{\mathrm{L}}\right.\right.\right.}{\partial \mathrm{x}_{\mathrm{j}}}$} \\
\hline & $\partial \mathrm{E}(\mathrm{y})$ & $\partial \mathrm{E}\left(\mathrm{y}^{*}\right)$ & $\partial\left[\left(\varphi\left(\mathrm{Z}_{\mathrm{U}}\right)-\varphi(\mathrm{Z}\right.\right.$ & $\partial \mathrm{E}(\mathrm{y})$ & $\partial \mathrm{E}\left(\mathrm{y}^{*}\right)$ & $\partial\left[\left(\varphi\left(\mathrm{Z}_{\mathrm{U}}\right)-\varphi\right)^{\prime}\right.$ & $\partial \mathrm{E}(\mathrm{y})$ & $\partial \mathrm{E}\left(\mathrm{y}^{*}\right)$ & \\
\hline & $\partial \mathrm{x}_{\mathrm{j}}$ & $\partial x_{j}$ & $\partial \mathrm{x}_{\mathrm{j}}$ & $\partial x_{j}$ & $\partial x_{j}$ & $\partial \mathrm{x}_{\mathrm{j}}$ & $\partial \mathrm{x}_{\mathrm{j}}$ & $\partial x_{j}$ & \\
\hline AGEHH & 0.00069 & 0.00065 & 0.00028 & 0.00143 & 0.00125 & 0.00129 & 0.00145 & 0.00145 & 0.00000 \\
\hline SEXHH & 0.08161 & 0.07870 & 0.02020 & -0.01222 & -0.01062 & -0.01182 & 0.05157 & 0.05157 & 0.00002 \\
\hline EDUCLHH & 0.00470 & 0.00444 & 0.00193 & 0.00659 & 0.00577 & 0.00593 & 0.00879 & 0.00879 & 0.00000 \\
\hline FOEC & 0.00520 & 0.00491 & 0.00213 & 0.01600 & 0.01401 & 0.01441 & 0.01709 & 0.01709 & 0.00001 \\
\hline PONFAC & 0.04681 & 0.04459 & 0.01577 & 0.03628 & 0.03215 & 0.02901 & 0.06484 & 0.06483 & 0.00004 \\
\hline SOILFERT & 0.03722 & 0.03550 & 0.01194 & 0.00271 & 0.00237 & 0.00241 & 0.02524 & 0.02524 & 0.00001 \\
\hline LANDFR & -0.01333 & -0.01257 & -0.00546 & -0.00078 & -0.00069 & -0.00071 & -0.00817 & -0.00816 & -0.00000 \\
\hline
\end{tabular}

Note: Marginal effects are computed only for significant variables and values under column $\frac{\partial \mathrm{E}(\mathrm{y})}{\partial \mathrm{x}_{\mathrm{j}}}$ shows (Total change), $\frac{\partial \mathrm{E}\left(\mathrm{y}^{*}\right)}{\partial \mathrm{x}_{\mathrm{j}}}$ shows $($ Expected change $)$ and $\frac{\partial\left[\left(\varphi\left(\mathrm{Z}_{\mathrm{U}}\right)-\varphi\left(\mathrm{Z}_{\mathrm{L}}\right)\right]\right.}{\partial \mathrm{x}_{\mathrm{j}}}$ shows (change in probability).

Source: Model result 


\section{REFERENCES}

AIGNER, D., LOVELL, C. and SCHMIDT, P. (1977). Formulation and estimation of stochastic production function models. Journal of Economics. 6(1):21-37. DOI: https://doi.org/10.1016/0304-4076(77)90052-5

AHMED, B., HAJI, J. and GETA, E. (2013). Analysis of Farm Households' Technical Efficiency in Production of Smallholder Farmers: The Case of Girawa District, Ethiopia. American-Eurasian J. Agric. \& Environ. Sci., 13 (12): $\quad$ 1615-1621.

DOI:

10.5829/idosi.aejaes.2013.13.12.12310

AHMED, M. H., LEMMA, Z. and GETA, E. (2015). Measuring Technical, Allocative and Economic Efficiency of Maize Production in Subsistence Farming: Evidence from the Central Rift Valley of Ethiopia. Applied Studies in Agribusiness and Commerce. DOI: 10.19041/APSTRACT/2015/3/9

ALEMU, G. and HAJI, J. (2016). Economic Efficiency of Sorghum Production for Smallholder Farmers in Eastern Ethiopia: The Case of Habro District. Journal of Economics and Sustainable Development. Vol.7. No.15, 2016. p. 44-51. Retrieved from https://www.iiste.org/Journals/index.php/JEDS/article/vi ewFile/32625/33515

ALI, A. A., IMAD, E. E. and YOUSIF, A.K. (2012). Economic efficiency of wheat and faba bean production for small scale farmers in Northern state of Sudan. Journal of animal \& plant sciences, 22(1): page: 215-223. thejaps.org.pk/docs/v-22-1/24.pdf

ASSEFA, A. (2016). Technical Efficiency of Smallholder Wheat Production in Soro District of Hadiya Zone, Southern Ethiopia. MSc. Thesis Haramaya University.

AWOL, A. (2014). Economic Efficiency of Rain-Fed Wheat Producing Farmer's in North Eastern Ethiopia: The Case of Albuko District. MSc Thesis Presented to the School of Graduate Studies, Haramaya University.

BATTESE, G.E. and COELLI, T.J. (1995). A model for technical inefficiency effects in a stochastic frontier production function for panel data. Empirical Economics, 20: $\quad$ pp; 325-332. DOI: https://doi.org/10.1007/BF01205442

BESHIR, H. (2016). Technical Efficiency Measurement and Their Differential in Wheat Production: The Case of Smallholder Farmers in South Wollo. Wollo University, Department of Agricultural Economics, P.O. Box 1145, Ethiopia. International Journal of Economics, Business and Finance Vol. 4, No. 1, pp. 1-16. Available online at http://ijebf.com/

CSA (2017). Agricultural Sample Survey 2016/2017 (2009 E.C.): Volume I - Report on area and production of major crops (Private peasant holdings, Meher season). Statistical Bulletin, Central Statistical Agency, Addis Ababa, Ethiopia.

DEGEFA, K., JALETA, M. and LEGESSE, B. (2017). Economic efficiency of smallholder farmers in maize production in Bako Tibe district, Ethiopia. Development Country Studies. Vol. 7, No. 2. https://www.iiste.org/Journals/index.php/DCS/article/vie wFile/35296/36318

FAO (Food and Agriculture Organization) (2015). Food Balance Sheets. FAOSTAT. Rome.
FEKADU, G. and BEZABIH, E. (2008). Analysis of Technical Efficiency of Wheat Production: A Study in Machakel Woreda, Ethiopia. MSc. Thesis Presented to the School of Graduate Studies, Haramaya University.

GETA, E., BOGALE, A., KASSA, B., and ELIAS, E. (2013). Productivity and efficiency analysis of smallholder maize producers in Southern Ethiopia. Journal of Human Ecology. 41(1):67-75. DOI: https://doi.org/10.1080/09709274.2013.11906554

GOULD, B. W., SAUPE, W. E. and KLEMME, R. M. (1989). Conservation tillage: the role of farm and operator characteristics and the perception of soil erosion. Land Economics, 65(2):167-182. DOI: 10.2307/3146791

GREENE, W. H. (2003). Econometric Analysis, $5^{\text {th }}$ ed. Pearson Education Inc., Upper Saddle

HAJI, J. (2008). Economic Efficiency and Marketing Performance of Vegetable Production in the Eastern and Central Parts of Ethiopia; Doctoral Thesis, Swedish University of Agricultural Sciences, Uppsala, Sweden.

KELEMU, K. and NEGATU, W. (2016). Analysis of levels and determinants of technical efficiency of wheat producing farmers in Ethiopia. African Journal of Agricultural Research. Vol. 11(36), Pp. 3391-3403. https://doi.org/10.5897/AJAR2016.11310

KITILA, G.M. and ALEMU, B. A. (2014). Analysis of Technical Efficiency of Small Holder Maize Growing Farmers of Horo Guduru Wollega Zone, Ethiopia: A Stochastic Frontier Approach. Science, Technology and Arts Research Journal, Vol 3, No 3 (2014) pp 204-212. DOI: http://dx.doi.org/10.4314/star.v3i3.33

MADDALA, G. S. (1999). Limited dependent variable in econometrics. Cambridge University Press, New York.

MEFTU, A. (2016). Economic Efficiency of Groundnut Production: The Case of Gursum District, East Hararghe Zone, Oromia National Regional State, Ethiopia. MSc. thesis. Haramaya University, Ethiopia.

MEKONNEN, E., GETA, E. and LEGESSE, B. (2015). Economic Efficiency of Sesame Production in Selamago District, Southern Ethiopia .Journal of Agricultural Sciences, $\quad 2(1)$ : $\quad 8-21$. 10.18488/journal.68/2015.2.1/68.1.8.21

MESFIN, O. G. (2015). Bread wheat production in small scale irrigation users agro-pastoral households in Ethiopia: Case of Afar and Oromia regional state. International Journal of Agricultural Economics and Extension, $\quad$ Vol.3 (5), pp.144-150. https://juniperpublishers.com/ijesnr/pdf/IJESNR.MS.ID. 555932.pdf

MINOT, N., WARNER, J., LEMMA, S., KASA, L., ABATE, G. T., A. and RASHID, S. (2015). The Wheat Supply Chain in Ethiopia: Patterns, Trends, and Policy Options. International Food Policy Research Institute (IFPRI) Washington, DC. 62 pp.

MUSTEFA, B. (2017). Economic Efficiency of Maize Producing Farmers in Chole districts, East Arsi Zone, Oromia National Regional State, Ethiopia. MSc. Thesis presented to school of graduate studies, Haramaya University.

NIGUSU, A. (2018). Economic Efficiency of smallholder Teff Production: The Case of Debra Libanos District, 
Oromia National Regional State, Ethiopia. MSc. Thesis, Jimma University.

SISAY, D., HAJI, J., GOSHU, D. and EDRISS, A.K. (2015). Technical, allocative, and economic efficiency among smallholder maize farmers in Southwestern Ethiopia. Journal of Development and Agricultural Economics, Vol. 7(8): pp 283-292. DOI: https://doi.org/10.5897/JDAE2015.0652

SOLOMON, B. (2012). Economic efficiency of wheat seed production in the case of smallholders in west Gojjam zone. M.Sc. thesis presented to the School of Graduate Studies, Haramaya University, Ethiopia.

TIRUNEH, W. G. and GETA, E. (2016). Technical Efficiency of Smallholder Wheat Farmers: The Case of Welmera District, Central Oromia, Ethiopia. Journal of Development and Agricultural Economics. Vol. 8(2), pp.39-51. DOI: $10.5897 /$ JDAE2015.0660

UNDP (United Nations Development Programme) (2018). Ethiopia's progress to warding eradicating poverty. Paper to be presented to the Inter-Agency Group Meeting on the Implementation of the Third United Nations Decade for the Eradication of Poverty (20182027) Addis Abeba, Ethiopia.
WFP (Food and Agricultural Organization and World Food Programme) (2012). Crop and Food Security Assessment Mission to Ethiopia. Special Report of Food and Agriculture Organization and World Food Programme.

YAMANE, T. I. (1967). Statistics: An Introductory Analysis $2^{\text {nd }}$ Edition. New York, Harper and Row.

YAMI, M., SOLOMON, T., BEGNA, B., FUFA, F., ALEMU, T. and ALEMU, D. (2013). Source of technical inefficiency of smallholder wheat farmers in selected waterlogged areas of Ethiopia: A translog production function approach. African Journal of Agricultural $\begin{array}{llll}\text { Research. } & \text { Vol. } & \text { 8(29). }\end{array}$ https://doi.org/10.5897/AJAR12.2189 